\section{ENTRE LA «CULTURA AUTÓCTONA» $Y$ LA «NATURALEZA INTRODUCIDA»: NOCIONES DE CONSERVACIÓN EN EL PARQUE NACIONAL TIERRA DEL FUEGO'}

BETWEEN «NATIVE CULTURE» AND

«INTRODUCED NATURE»: CONSERVATION

NOTIONS IN TIERRA DEL FUEGO NATIONAL PARK

MARÍA VICTORIA VIDELA .

MARIANO MELOTTO •

Instituto de Cultura Sociedad y Estado -

Universidad Nacional de Tierra del Fuego (ICSE-UNTDF)

mvvidela@untdf.edu.ar

mmelotto@untdf.edu.ar

JOSÉ ANTONIO GARRIGA ZUCAL .

Instituto de Altos Estudios Sociales -

Universidad Nacional de San Martín (IDAES-UNSAM)

garrigajose@hotmail.com

\section{Resumen}

¿Cómo está representada la cultura y naturaleza en el Parque Nacional Tierra del Fuego? Nos interesa abordar este interrogante para reflexionar sobre las áreas protegidas y, desde allí analizar, las políticas Estatales de intervención en la problemática de la conservación ambiental. Estudiaremos, con este objetivo, la sala de Interpretación Maiá-Kú y la folletería que se ofrece en este parque nacional. Entendemos que la dicotomía cultura-naturaleza supone un tipo particular de interpretación de la conservación ambiental.

\section{Descriptores}

Conservación / Parque Nacional / Cultura / Naturaleza / Estado

\section{ESTUDIOS SOCIALES}

revista universitaria semestral ·

año XXXI $\cdot n^{\circ} 60 \cdot$ Santa Fe $\cdot$ Argentina

Universidad Nacional del Litoral ·

enero-junio · 2021 [ ISSNe 2250-6950 ]

DOI [ 10.14409/es.v60i1.8709] · PP [ 49-71]

๑(1) @ (

\begin{abstract}
How are culture and nature represented in Tierra del Fuego National Park? The interest in addressing this question is to reflect on protected areas and, from there, analyze State policies of intervention in environmental conservation issues. With this objective we will study the Maiá-Kú interpretive center and the brochures offered in this national park. We understand that the culture-nature dichotomy is a particular type of interpretation of environmental conservation
\end{abstract}

\section{Describers}

Conservation / National Park / Culture / Nature / State

Recibido: 29 / $11 / 2019$ Aprobado: $31 / 10 / 2020$

1] El siguiente trabajo se enmarca en el Proyecto de Investigación y Desarrollo Tecnológico/Social (PIDUNTDF «B») 2018, dirigido por el Dr. Mariano Melotto. 


\section{INTRODUCCIÓN}

Proponemos analizar las representaciones de cultura y naturaleza que aparecen en el Parque Nacional Tierra del Fuego. Para ello estudiaremos la sala de interpretación Maiá-Kú y la folletería que se ofrece a quienes visitan el parque como discursos o narrativas públicas, formados por la combinación de elementos diversos, a partir de los cuales la Administración de Parques Nacionales (en adelante APN) construye y busca instalar, un sentido sobre lo que es el Parque Nacional Tierra del Fuego (en adelante PNTDF) y por qué es importante su existencia.

Partimos de una conceptualización de las áreas protegidas entendidas como formas particulares de construcción y apropiación de territorios por parte de los Estados. Pero, al mismo tiempo, destacamos su carácter de arenas políticas donde diversas formas de significar y actuar sobre el territorio se ponen en juego a partir de la participación de comunidades locales, organizaciones no gubernamentales, empresas multinacionales, entre otros actores relevantes (FERRERo, 20I8). Las áreas protegidas se clasifican, a su vez, en diferentes categorías de manejo según «su objetivo principal, otros objetivos secundarios, rasgos distintivos, papel en el paisaje terrestre o marino, elementos únicos que hacen singular a la categoría y acciones que son compatibles o incompatibles.» (Dudley, 2008 en CARUso, 20I5: I34). Los parques nacionales constituyen una de estas categorías de manejo. De acuerdo con el Artículo $4^{\circ}$ de la actual Ley de Parques Nacionales $N^{\circ}$ 22.35I, serán parques nacionales...

«las áreas a conservar en su estado natural, que sean representativas de una región fitozoogeográfica y tengan gran atractivo en bellezas escénicas o interés científico, las que serán mantenidas sin otras alteraciones que las necesarias para asegurar su control, la atención del visitante y aquellas que correspondan a medidas de Defensa Nacional adoptadas para satisfacer necesidades de Seguridad Nacional. En ellos está prohibida toda explotación económica con excepción de la vinculada al turismo, que se ejercerá con sujeción a las reglamentaciones que dicte la autoridad de aplicación»².

2] Obtenido de https://www.argentina.gob.ar/normativa/nacional/ley-22351-16299/actualizacion (Ultimo ingreso: 16/08/2020) 
Nuestro objetivo es analizar cómo, en el territorio que conforma el PNTDF, el Estado diferencia la naturaleza de la cultura y cómo elabora las estrategias de legitimación del cuidado de la segunda sobre la primera.

La modernidad separó la naturaleza de la cultura, construyó una férrea frontera (DESCOLA, 2005; LATOUR, 2004). Propietaria de la cultura, la razón moderna concibió a la naturaleza como externa, inerte y pasiva. La escisión aseguraba el dominio de la razón sobre lo no humano. El conocimiento científico y el descubrimiento de «las leyes de la naturaleza» jerarquizó, legitimó un dominio y diferentes formas de intervención. Por ello, desde entonces, la naturaleza debe ser cuidada y protegida, su pasividad habilitó el cuidado.

En este trabajo analizaremos la representación y separación del binomio cultura-naturaleza y las ideas de conservación que aparecen en el PNTDF. Por tanto, nos proponemos primero realizar un análisis de la sala de interpretación Maiá-Kú con el objeto de comprender cómo se da la separación naturaleza y cultura. Para luego continuar pensando cómo son presentados los pueblos originarios que habitaron estas tierras antes de "la llegada de la cultura» y las especies «invasoras» de la naturaleza. Finalizaremos analizando el lugar protagónico del Estado en la construcción de una naturaleza a proteger.

Para analizar las representaciones de la sala de interpretación y de la folletería que se realiza sobre los antiguos habitantes y las especies invasoras usaremos la noción de cuasi-culturas y cuasi-naturaleza. Hemos creado estas nociones para dar cuenta de los híbridos que habitan la dicotomía naturaleza/cultura. Estas nociones son deudoras de Latour (2004) y del concepto de cuasi-objeto. Para Latour la modernidad es un sistema clasificatorio que configuró la disociación naturaleza y sociedad. Disociación que nunca fue real y por ello titula a su obra: «Nunca fuimos modernos». Un sistema de clasificación imperfecto, habitado por híbridos. Latour nombra cuasi-objetos a estos híbridos, los que no tienen un espacio definido, no son del todo sujetos ni del todo cosas. Las nociones de cuasi-culturas y cuasi-naturaleza, toman esta idea de cuasi-objetos, y nos permitirán iluminar/analizar, por sus imperfecciones, las operaciones de separación de la naturaleza y la cultura.

En este trabajo hemos utilizado un abordaje metodológico cualitativo. Articulamos las visitas al centro de interpretación Maiá-Kú, recorriendo el lugar y fotografiándolo en recurrentes oportunidades, con el estudio de la folletería que reciben los visitantes al abonar la entrada al parque. Los folletos abordados son dos 
trípticos realizados por la APN. Uno de estos trípticos que se denomina «Información general», fue realizado en el 2018 y tiene información del parque distribuida en siete ítems: vegetación, fauna, turbales, animales introducidos, costa marina y recomendaciones. El segundo tríptico fue realizado en el 2013 se denomina «Fauna nativa: Huillín (Lontra provocax)» y posee información sobre una particular especie de nutria que vive exclusivamente en ambientes acuáticos de la región patagónica.

\section{EN EL FIN DEL MUNDO}

La creación del primer parque nacional argentino data del año 1903 a partir de la donación de tierras hecha por el Perito Francisco P. Moreno en la región del lago Nahuel Huapi (erize, CANeVAri, CANEVAri, COSTA y RUMbOll, [I98I] 1993). Eugenia Scarzanella identifica los orígenes de los parques nacionales en nuestro país dentro de «un movimiento de alcance continental, que apunta a la conservación de las bellezas naturales, cuyo principal inspirador son los Estados Unidos» (SCARZANELla, 2002: 18). De acuerdo con la bibliografía que aborda esta cuestión, el origen de los parques nacionales en nuestro país respondió a necesidades heterogéneas pero relacionadas entre sí (SCARZANELLA 2002; CARRERAS DOALLO 2OI2; PIGLIA 2OI2; CARUSO 2OI5). Así, a la búsqueda de conservar lugares con paisajes sobresalientes por su atractivo estético, se sumaba la necesidad de un Estado nacional que, ya habiendo consolidado su gobierno central en Buenos Aires, buscaba extender el ejercicio de su soberanía al resto de su extensión territorial. En el mismo sentido, la página web de la Administración de Parques Nacionales comenta que, la donación de Moreno, perseguía objetivos de preservación «aunados a un claro sentido de soberanía ${ }^{3}$.

Estas acciones, tendientes a consolidar una nación, perseguían como parte de sus objetivos la creación de una identidad nacional. También aquí, los parques nacionales desempeñaron un papel importante ya que, ante la negación del pasado indígena, se echó mano al recurso de significar la identidad nacional en la magnanimidad de la naturaleza (PIGLIA, 2OI2). Scarzanella describe claramente estos procesos cuando afirma que...

3] Disponible en: https://www.parquesnacionales.gob.ar/institucional/historia-institucional/ (Ultimo ingreso: 17/12/2017). 
«No es casualidad que en América Latina el primer parque nacional fuese proyectado y realizado justamente por la Argentina, país de frontera e inmigración al igual que los Estados Unidos. En Argentina, como en el gran país del norte, el tiempo histórico era breve, no había grandes civilizaciones precolombinas con ruinas monumentales capaces de consagrar la nobleza de los nuevos países. Había que buscar en las bellezas naturales las razones de la propia identidad.» (SCARZANELLA, 2002: 6).

En 1928 el Estado argentino procede a la compra de 75.00o hectáreas en Misiones para la instauración de un segundo parque nacional y para la creación de una colonia militar. Pasarían seis años para que se creara el Parque Nacional Iguazú. Esto fue posible gracias a la sanción de la primera Ley de Parques Nacionales, $\mathrm{N}^{\circ}$ I2.IO3 del 29 de septiembre de 1934, normativa que además creaba la Dirección de Parques Nacionales estableciendo su competencia, jurisdicción, atribuciones y deberes. Estas facultades asignadas a dicha dirección daban cuenta de múltiples objetivos tales como, la conservación ambiental, el fomento del conocimiento, el desarrollo del turismo y otras actividades económicas, como así también la afirmación de la soberanía nacional mediante su rol como representante estatal en regiones generalmente limítrofes e inhóspitas ${ }^{4}$.

4] En el Artículo N ${ }^{\circ} 17$ referido a las atribuciones y deberes aparecen, entre otras, las de: «Proteger, conservar y fomentar la fauna y flora de los parques y reglamentar dentro de ellas la pesca y la caza; « «Estimular los estudios e investigaciones científicas en las reservas a su cargo, bajo la condición de que sus beneficios alcancen a las universidades e instituciones públicas;» «Promover el progreso y desarrollo de los parques mediante la construcción de caminos, puentes, escuelas, líneas telegráficas y telefónicas, muelles, puertos, desagües, obras sanitarias...»; "Otorgar y reglamentar las concesiones sobre la construcción de hoteles, viviendas, restaurantes, funiculares, alambrecarriles, estaciones para el servicio de automóviles, etcétera...;» «Ejecutar periódicamente un censo de la población, movimiento y riquezas inherentes a los parques y reservas;» «Proceder al desalojo de los intrusos en tierras de dominio público que a su juicio no convengan a los intereses de los parques y reservas;» " Velar por el cuidado y conservación de los bosques...»; «Resolver sobre la toponimia en los parques y reservas nacionales, procurando restablecer la original;» «Efectuar la delimitación y amojonamiento de los perímetros de los parques y reservas, así como las mesuras que sean necesarias, incluso el trazado de centros de población...;» «Establecer multas de 500 pesos moneda nacional, en los casos de transgresión a los reglamentos y demás disposiciones que se dicten para el mejor gobierno de los parques y reservas...; entre otros. 
La historia del PNTDF empieza, según se puede leer en uno de los carteles de la sala de interpretación, con dos intentos fallidos de creación. El primero en marzo de I9ro cuando se sanciona un Decreto s/n que reservaba «para Parques Nacionales una superficie aproximada de 350.000 hectáreas, rodeando el Lago Fagnano». Sin embargo, en 1935 el artículo 26 del Decreto No 55177 reglamentario de la Ley No I2.IO3 de Parques Nacionales lo deja sin efecto. El segundo intento data del 25 de enero de 1946, cuando por Decreto No 2.524 se disponía la creación del Parque Nacional con límites diferentes a los actuales. Sin embargo, el 4 de septiembre de I947 fue dejado sin efecto por Decreto No 26.933 (OYOLA-YEMAIEL, 2000: I42).

Finalmente, en 1960, durante el gobierno de Ernesto Manuel Campos, se aprueba la Ley $\mathrm{N}^{\circ}$ I5.554 que crea el actual PNTDF, con una superficie de 68.909 hectáreas. En el «Plan de manejo del Parque Nacional Tierra del Fuego» de la Administración de Parques Nacionales (2007), se puede leer que el parque fue creado con el objetivo de conservar una porción representativa de los bosques subantárticos correspondientes al sector más austral del Distrito Biogeográfico Magallánico. Es importante mencionar que más allá de los objetivos conservacionistas, se imponía entonces un modelo de creación de áreas protegidas impulsada por la necesidad de consolidación de soberanía territorial en las fronteras con el vecino país de Chile, de la mano del turismo como motor de desarrollo económico (OYOLA-YEMAIEL, 2000; Reboratti, 2000). Más tarde, en I990, el Decreto No 2.I49 designa un sector al norte y sur del Lago Fagnano en el límite con la República de Chile como reserva natural estricta. Por último, en 1994, mediante el Decreto No 453 se modifican los límites de esta y se crea una reserva natural silvestre.

Es importante destacar que la creación del parque significó un cambio de las actividades productivas que se realizan en lo que hoy es el territorio del PNTDF. Desde I88I funcionó en Lapataia el primer aserradero a gran escala de Tierra del Fuego. Asimismo, en la década de 1960 ya existía la Pesquera Lapataia, dedicada a la pesca y procesamiento de moluscos, ubicada en la bahía homónima5. Con la creación del PNTDF estas actividades económicas primarias dieron paso a actividades del sector terciario relacionadas con el turismo que perduran hasta el día de hoy. Según expresa

5] Obtenido de: UCAR Plan de Mejora Competitiva. Cluster de la Pesca Artesanal de Tierra del Fuego. Ministerio de Agricultura, Ganadería y Pesca. Presidencia de la Nación. Disponible en: https://industria. tierradelfuego.gob.ar/wp-content/uploads/2014/03/PMC-cluster-PESCA-ARTESANAL-20131201. pdf (Ultimo ingreso: 9/6/2019) 
el cartel de la sala dedicado a la historia del parque «el turismo en la zona se inicia en I96I, de la mano de las regalías petroleras.» De hecho, el actual centro de visitantes Alakush $^{6}$ donde se emplaza la sala de interpretación fue originalmente una hostería ${ }^{7}$. Además de la sala de interpretación, en Alakush se encuentra una confitería que ocupa la mayor parte del espacio, baños públicos y una tienda de suvenires. Por último, en un entrepiso al que se accede por una escalera de la confitería hay una muestra permanente sobre los pueblos originarios de Tierra del Fuego ${ }^{8}$.

En un trabajo publicado en 2015, Caruso construye una periodización histórica para la creación de parques nacionales en nuestro país a partir de la cual establece tres etapas caracterizadas, cada una, por determinadas políticas públicas en torno a los parques junto a particulares vertientes teóricas relacionadas a la conservación. El primer período comprende del año 1934 a 1944, domina aquí el Enfoque Preservacionista a partir del cual se buscaba proteger paisajes de gran belleza escénica de la alteración que pudieran sufrir por las actividades antrópicas. Durante este período se sanciona la Ley de Parques, se crean los primeros parques nacionales de Argentina, persiguiendo, junto con los objetivos conservacionistas ya mencionados, la consolidación de la soberanía nacional. Asimismo, se da origen a la Dirección Nacional de Parques que jugó un importante rol en la fundación de escuelas, iglesias, hospitales, villas turísticas, infraestructura vial y hotelera (CARUSO, 2015: I45). Un segundo período, que el autor identifica entre los años 1945 y 1979, está caracterizado inicialmente por el acceso de los sectores asalariados al turismo en sus tiempos de ocio y el desarrollo de una importante infraestructura vial y turística, seguido luego por un contexto nacional de sucesivas dictaduras militares que significaron un marcado retroceso en materia de conservación y parques nacionales en nuestro país. Si bien Caruso reconoce que en este segundo período se continuaron creando parques en áreas limítrofes de la Patagonia —es el caso del PNTDF—, se destacó sin embargo por un cambio en la perspectiva conservacionista que dió prioridad al Enfoque del Equilibrio. Esta perspectiva valora científicamente y como objetivo de conservación los ecosistemas junto a las especies que los integran. Se impulsó

6] Nombre con el que en lengua yámana se denomina a una especie de pato conocida como «pato vapor». 7] Plan de manejo Parque Nacional Tierra del Fuego. Administración de Parques Nacionales (2007)

8] En este trabajo no vamos a analizar dicha muestra ya que, tanto por su ubicación poco visible como por el hecho de no ser de acceso gratuito, resulta en que sea visitada por un número muy reducido de personas en comparación con la sala Maiá-Kú. 
entonces en nuestro país la creación de parques en el interior del territorio que, antes que proteger paisajes de inusual belleza, buscaban «conservar una porción significativa de todos los ambientes presentes en el territorio nacional» (CARUso, 2015: 147). Finalmente, un tercer período hace su aparición en 1980 y se extiende hasta el presente. Este momento se caracteriza por la proliferación de nuevas áreas protegidas, promovidas en muchas ocasiones por organizaciones no gubernamentales dedicadas a la conservación, las que además se consolidan como nuevos actores sociales característicos del período. Es además en esta etapa que, a partir del 2009, se crean las primeras áreas protegidas para conservar la ecorregión Mar Argentino. La perspectiva conservacionista que domina este tercer período es el Enfoque Desarrollista que gira en torno a la noción de desarrollo sustentable. Esta perspectiva niega la posibilidad de un ambiente que no sea afectado por las acciones de las sociedades humanas, proponiendo un manejo del ambiente y los recursos que reduzca al mínimo los efectos antrópicos a partir de la limitación y racionalización de las actividades socioproductivas. Tomando en cuenta la periodización de Caruso podemos considerar que el PNTDF es un caso en el que confluyen características de los dos primeros períodos. Su creación responde, por un lado, a motivos de soberanía nacional en territorios donde los conflictos de límites con el vecino país de Chile se extendieron hasta el año 1978. Y, al mismo tiempo, no deja de ser un ejemplo de un ecosistema no conservado hasta entonces ya que es el único en que se encuentran la cordillera con el ambiente costero marino. Como ya dijimos más arriba su creación implicó el cese de actividades extractivas dando paso al turismo como impulsor de la economía, y junto a ello la creación de infraestructura hotelera, mejora de caminos y servicios para el turista, todo lo cual constituye aspectos que Caruso reconoce como políticas públicas comunes a ambos períodos.

\section{LA SALA DE INTERPRETACIÓN MAIÁ-KÚ}

Descola hace una descripción del Museo de Ciencias Naturales de La Plata y analizando la disposición de lugares interpreta que la misma «refleja bien el orden del mundo que nos rige desde hace más de dos siglos» (DESCOLA, 2005: 94). ¿Cuál es este orden? La planta baja del museo está enteramente dedicada a la naturaleza y en sus galerías aparecen la mineralogía, paleontología, zoología y botánica ordenadas rigurosamente según categorías y taxonomías. En el primer piso aparecen 
los hombres y sus formas culturales, sin una categorización tan exhaustiva y exhibiendo un camino evolutivo hacia la civilización. El orden que presenta el museo es una separación tajante y jerárquica. La naturaleza es el cimiento de la cultura, pero está por debajo de la civilización, que la ordena y categoriza.

La sala de interpretación Maiá-Kú del PNTDF se encuentra en el interior del centro de visitantes Alakush ubicado a $8,5 \mathrm{~km}$. desde el ingreso al Parque. La sala es una habitación rectangular con un panel curvo en el medio y a lo largo, que funciona como división parcial (ver plano referenciado) ordenando la sala en dos mitades longitudinales. Asimismo, las paredes están recubiertas de posters o láminas de diferentes colores según la temática que abordan. Estos posters constan de imágenes y textos en español junto a su traducción en inglés y, en algunos casos, incluyen pequeñas vitrinas donde se exhiben objetos. Al llegar a la entrada de la sala una lámina da la bienvenida, explica el significado de la expresión Maiá-Kú e indica, mediante una flecha, por dónde ingresar. Así, comenzando por la mitad de la izquierda, la sala propone un sentido de circulación a favor de las agujas del reloj.

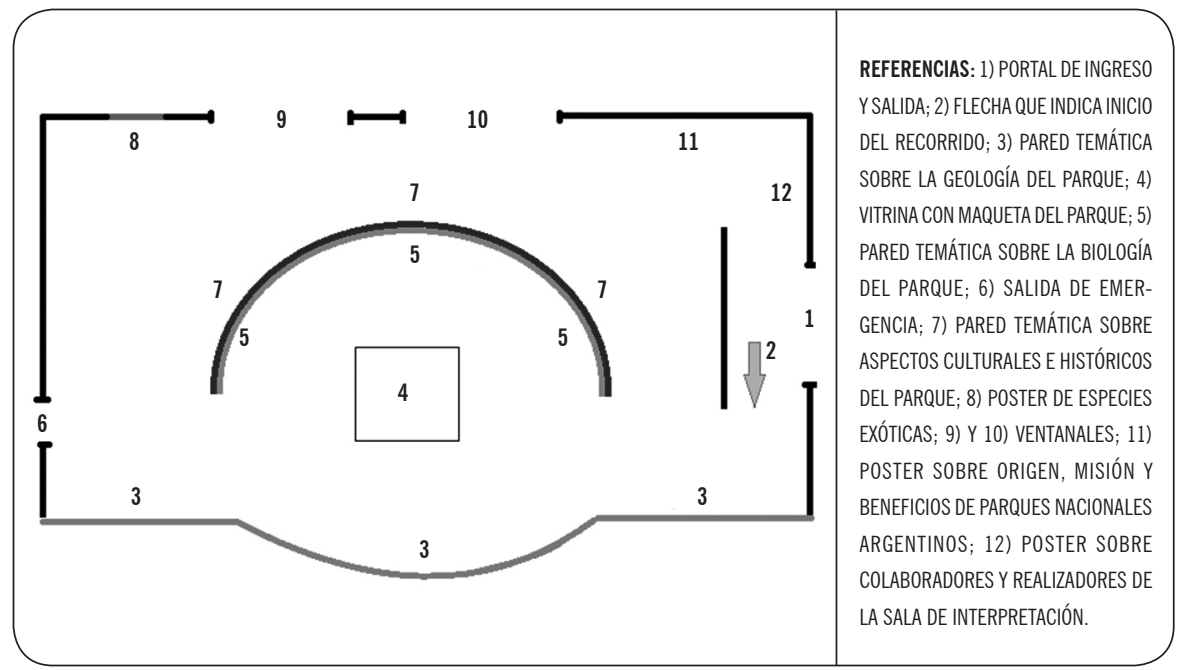

9] Según el poster de bienvenida esta es la expresión con la cual los yaghanes describían «su forma de observar su mundo", estando "atento a todo lo que te rodea, grande o pequeño, cercano o lejano, vivo o inanimado; porque todo está íntimamente relacionado». 
Plano referenciado de la sala de interpretación. Este croquis no tiene una escala que se corresponda con la sala real, nuestra intención al presentarlo ha sido ayudar al lector en la descripción de la sala e indicar la distribución de las temáticas y objetos exhibidos. Elaboración propia.

$\mathrm{Ni}$ bien ingresamos, la primera lámina cuenta que el PNTDF «es el único de nuestro país donde se encuentran el bosque, el mar y la montaña» y anticipa el criterio temporal que ordena toda la sala cuando invita al visitante a acompañar «a descubrir cómo comenzó esta historia que, en sus últimos capítulos incorpora la presencia del hombre y su habilidad para adaptarse a las particulares condiciones ambientales de la región».

Siguiendo el orden de circulación propuesto, la primera pared está formada por láminas con bordes en color azul que tratan sobre la geología del Parque. Se ofrece allí una explicación general sobre las glaciaciones cuaternarias y los glaciares, con imágenes que muestran cuál habría sido la extensión de los hielos en el extremo sur del continente hace 25.000 años durante la última glaciación. A continuación, se achica la escala geográfica para mostrar y explicar cómo esa glaciación modeló el paisaje de Tierra del Fuego. La última lámina de esta pared da cuenta de las particularidades de la formación del lago Roca o Acigami que se encuentra dentro del Parque.

A espaldas de esta "pared geológica», sobre la faz izquierda del panel divisorio (lado cóncavo), encontramos que las láminas son de color verde y están referidas a la biología del Parque. En este caso el sentido de circulación para su lectura es opuesto a los paneles sobre geología. Es decir que, luego de leer el último poster azul, el primer poster sobre biología está a espaldas del/la visitante. El relato en este caso comienza con la descripción del bosque fueguino y pasa luego a detallar los ambientes de turba, de altura y de costa. Las descripciones incluyen aspectos de la flora y fauna de cada ambiente. En esta pared se encuentran dos cajas exhibidoras, una está abierta y contiene una muestra de turba que los/as visitantes pueden tocar y en la otra hay un huillín (Lontra provocax $)^{10}$ embalsamado.

10] Entre los folletos que ofrece el parque, hay uno dedicado enteramente a esta especie. Allí, puede leerse que: el huillín es un tipo de nutria o «lobito de río» que habita en las regiones patagónicas de Argentina y Chile. Se aclara también que, a pesar de ser una especie típica de aguas dulces, en Tierra del Fuego se adaptó a las costas del archipiélago del Beagle. La especie solía ser abundante en todo el bosque patagónico, pero está actualmente en riesgo de extinción y solo se la encuentra en los parques nacionales Nahuel Huapi, Lanín y Tierra del Fuego (donde es muy difícil de ver). 
El recorrido continúa girando hacia la derecha e ingresando en la segunda mitad de la sala de modo tal que queda expuesta la otra cara del panel curvo divisorio (lado convexo). Esta mitad hace referencia a aspectos culturales e históricos del parque. Aparece entonces un poster con bordes color violeta dedicado a los pueblos originarios que habitaron lo que hoy es el parque nacional (Imagen 2). Se titula «Canoeros del fin del mundo" y está compuesto por una breve descripción de los pueblos de la costa del Canal de Beagle, fotos etnográficas y tres cajas exhibidoras donde se ve material de concheros en una y reproducciones de puntas de arpón de hueso en las otras dos.

Siguiendo el recorrido de esa pared pueden verse 4 vitrinas, la primera contiene una réplica de una canasta yámana delante de una foto etnográfica donde se observa una canasta similar y un breve texto explicativo. La siguiente tiene muestras de carbón y cuenta que en el margen oeste de la bahía existía una carbonera para abastecer a los barcos que transportaban mercancías antes de la construcción de la Ruta Nacional 3. Las dos cajas siguientes refieren una al presidio y la última al aserradero que funcionó dentro de los márgenes actuales del Parque.

En el extremo último de este lado convexo del panel hay una lámina referida a la creación del PNTDF. Allí se hace mención al inicio de las actividades turísticas en el año 196r relacionadas a las regalías petroleras, se ofrecen algunos datos sobre las primeras instalaciones construidas en el parque y sobre la construcción del tramo final de la Ruta 3. Finalmente se hace una breve alusión al variado personal que trabaja actualmente en el parque.

En la pared que se ubica frente al lado convexo del panel divisorio recién descripto, encontramos, de izquierda a derecha, primero una lámina, luego dos ventanales y finalmente una lámina más. La primera lámina, que es de color rojo oscuro, se titula «Simpáticos pero problemáticos», y muestra cuales son las especies introducidas que habitan el parque, haciendo referencia a los problemas que ello trae aparejado (Imagen 3). Delante de este poster, apoyado en el piso, puede verse un tronco roído por castores. Le siguen los dos ventanales desde los que se puede apreciar el Río Lapataia y a continuación una lámina que resume los inicios de los parques nacionales de Argentina, la importancia de los mismos para nuestro país, las funciones de conservación y las posibilidades que ofrecen. Por último, antes de salir (por el mismo acceso por el que se ingresa) en otra lámina, se listan los agradecimientos, los nombres de quienes trabajaron en el armado de la sala indicando en cada caso su pertenencia institucional y, finalmente, algunas especies animales y vegetales presentes en el parque con sus nombres científicos. 


\section{LOS ANTIGUOS HABITANTES: LAS CUASI-CULTURAS}

Nos interesa en este apartado analizar las representaciones sobre los pueblos originarios que aparecen en la folletería que el parque nacional entrega a los visitantes, y en la sala de interpretación para entender cómo éstas operan en la separación naturaleza-cultura. La modernidad y su racionalidad no solo forjó este límite, sino que también fundó un orden para los humanos exóticos o marginales. Usaremos la noción de cuasi-culturas para reflexionar sobre las representaciones que aquí aparecen sobre los antiguos habitantes. Ubicados estos en la dicotomía moderna naturaleza/cultura más cerca de la primera que de la segunda.

Decíamos que en una de las láminas de la sala (Imagen 2) se abordan las formas de vida de los primeros pobladores de la Isla Grande de Tierra del Fuego, las imágenes muestran sus chozas, canoas y un hombre con un arpón en una posición de caza. En el espacio donde ahora está enclavado el parque nacional habitaron, según el folleto, los Yámanas presentes en la isla Grande de Tierra del Fuego desde hace alrededor de diez mil años. Los Yámanas eran cazadores de lobos marinos y recolectores de moluscos, su vivienda eran chozas «provisorias» y su vestimenta «se limitaba» a una capa corta de cuero de lobo marino. Señala que la "desaparición» ${ }^{11}$ de este pueblo empieza en i880 con la llegada de los primeros colonos.

Por otro lado, el folleto hace referencia a estos «antiguos habitantes» ahora desaparecidos en otra dimensión. En sus primeras líneas señala: «La variedad étnica de los grupos humanos que la habitaron, demuestra que ellos se relacionaron en forma íntegra y efectiva a un medio ambiente considerado por nosotros como bastante inhóspito».

Entendemos como sustantiva la noción de que los pueblos originarios tuvieron una relación «íntegra y efectiva» con el medio ambiente y, sin comprender cabalmente cuál es el sentido de esta relación, podemos afirmar, sin duda, que hay una visión idealizada de dicho vínculo. En el mismo sentido, en el texto aparece una referencia a una «relación ancestral con la naturaleza». En estas líneas la referencia a un «nosotros» que define el ambiente como inhóspito señala una diferencia, un límite. Una diferencia entre dos formas de vincularse con la naturaleza.

11] Es necesario mencionar dos cuestiones sobre la «desaparición». Primero que la idea de desaparición opaca el genocidio sobre los pueblos originarios y, segundo, que oculta, también, la existencia presente de comunidades originarias Shelk' nam y Yámanas que poseen incluso personería jurídica, como así también de descendientes que reclaman su identificación para con estos pueblos. Para mayor información recomendamos indagar en los trabajos de Hernán VIDAL (1993), BRIONES (2005) y GERRARD $(2014,2015,2017)$. 
Nos cabe hacer dos interpretaciones de la representación que hace el parque sobre estos pueblos originarios. Primero, cabe hacer referencia a las representaciones de las imágenes y los textos como cuasi-culturas. Estos «antiguos habitantes» son presentados casi desprovistos de manifestaciones culturales, ya que en el texto del folleto no se hace ninguna referencia ni a su organización social, ni familiar, ni a su mundo de creencias, ni a sus juegos. Las únicas referencias son para con los objetos que son presentados como «limitados» y «provisorios». Dando cuenta así de una pobreza material que parece ser el único correlato de la ausente dimensión simbólica y, por ende, cultural. Aquello que no se dice, las ausencias, también forma parte de la construcción de sentido.

En la sala de interpretación encontramos dos referencias a las formas culturales de los «antiguos habitantes». Un audio con lo que parece un canto Yámana recibe a los visitantes. Un texto hace referencia a este audio, muchas veces inaudible por las voces y gritos de los asistentes, nos dice:

«Si prestas atención, quizás puedas reconocer sus voces en el susurro del viento que las esparce por los valles, donde quizás todavía more Hãnnus, el gigante del bosque. Voces que, serpenteando por costas y bahías, todavía inquieten a Lakûma, el demonio marino. Voces que nos hablan de la tragedia de un pueblo que ya no existe. Es bueno escucharla..., es bueno tener memoria..., es bueno aprender...»

La vida espiritual de los pueblos Yámanas da cuenta de las formas culturales de los antiguos habitantes y remite, nuevamente, a su desaparición. Por otro lado, en la sala hay un arpón de miniatura que era utilizado para jugar. Aquí, el juego está asociado a un entrenamiento y aprendizaje en las actividades de caza, no se lo presenta como un juego en sí mismo sino refiriendo a un fin utilitario. Una vez más parece que estas cuasi-culturas tienen objetos «limitados». De esta manera, el relato que ofrece la sala ubica a los pueblos originarios lejos de la cultura y más cerca de la naturaleza. Son hombres, pero no son parte de la cultura separada de la naturaleza, son una cuasi-cultura. La mirada romántica para con su relación con la naturaleza encadena los sentidos de una interpretación que aleja a estos pueblos de la cultura escindida de la naturaleza y los acerca a esta. Los «antiguos habitantes» no son arcaicos temporalmente, ya que convivieron con los criollos, son culturalmente vetustos; tanto que si los ponemos en la escala evolutiva que ordena el pensamiento del sentido común están más cerca de la naturaleza que de 
la civilización. MALLIMACI BARRAL (2008), afirma que desde hace unos años y al igual que en el resto de la Patagonia, emergió en la ciudad de Ushuaia la demanda por incluir a los pueblos originarios en la memoria social a través de su mención en el espacio público (nombres de calles, plazas, etc.) como parte de una redefinición del sentido de «ser fueguino». En estos discursos los pueblos originarios se presentan como lo «verdaderamente» autóctono y, continúa,

«Si bien Onas (Selk'nam) y Yámanas han aparecido constantemente en los relatos históricos sobre Ushuaia lo hicieron muchas veces no como el «origen» de la ciudad sino como un dato de la «naturaleza». En las expediciones científicas y geográficas son «objetos» de indagación y conocimiento asimilándolos a la naturaleza, salvaje, desconocida, «vacía» que debía conocerse, civilizarse y poblarse.» (MALLIMACI BARRAL, 2008: 7)

Afirmamos que el relato que ofrece la sala de interpretación Maiá-Kú, presenta a las comunidades Selk'nam y Yámanas como un dato de la naturaleza, parte de lo «verdaderamente autóctono" y previo a lo "civilizado», o sea, como cuasi-culturas.

Segundo, nos interesa señalar que la representación romántica para con esta alteridad es el resultado de su supuesta «desaparición». Desaparecidos los pueblos originarios son representados de formas idealizadas. Las cuasi-culturas no son un riesgo y, por ello, son presentadas de estas maneras. MASOTTA (20I8) usa el concepto de reconocimiento o elogio negativo para señalar las formas dominantes y violentas que tienen los museos de representar a los pueblos originarios para silenciar sus reclamos y su historia. En nuestro caso el elogio negativo además de silenciar la historia de estos pueblos y los actuales reclamos, actúa silenciando su misma existencia, ya que al ser presentados como «desaparecidos» se sustrae a los actuales integrantes de dichas comunidades el reconocimiento como parte de las mismas. Es necesario mencionar en este punto los trabajos de Hernán VIDAL (I993), Claudia BRIONES (2005) y Cecilia GERRARD (2OI4, 20I5, 20I7) que analizan la construcción hegemónica de la alteridad indígena en Tierra del Fuego, destacando cómo los sectores de inmigrantes nacionales llegados con posterioridad a la sanción de la Ley de Promoción Industrial de I972, se apropiaron de la imagen de los indígenas «extintos» para la construcción de un nosotros regional. Estos autores denuncian un segundo etnocidio de naturaleza discursiva ${ }^{12}$ que, legitimado en parte por la academia, ubicaba a los indígenas en

12] Este genocidio discursivo sería posterior a las matanzas de nativos ejecutadas a finales de siglo 
el pasado, al no considerar a los contemporáneos «lo suficientemente puros como el indígena objetivado en las obras literarias y etnográficas, por lo que recibieron la denominación genérica de mestizos y descendientes» (GERRARD, 2OI4: 3).

En la misma línea traemos a DE CERTEAU (1999) quien sostiene que ciertas formas de lo popular se pueden transformar en objeto de estudio cuando han desaparecido, cuando han muerto y su conflictividad se ha desvanecido. Por ello, se refiere a «la belleza de lo muerto».

\section{LAS ESPECIES «INVASORAS»: CUASI-NATURALEZA}

En este último apartado deseamos mostrar cómo, desde la folletería y la sala de interpretación, se construye, justifica y legitima el rol del Estado en la conservación de la naturaleza. Un análisis de la sala de interpretación concibe la relación naturaleza-cultura en la misma línea que Descola menciona para el Museo de Ciencias Naturales de La Plata (2005). El recorrido se inicia en la naturaleza y concluye en la cultura, o mejor dicho en las culturas. Sin embargo, a diferencia del Museo de La Plata analizado por Descola la sala de interpretación Maiá-Kú del PNTDF finaliza en su recorrido con la justificación de la creación de las áreas protegidas. La jerarquización de la cultura sobre la naturaleza tiene que ver aquí con la necesaria protección y conservación que el Estado se autoimpone. Al respecto, la anteúltima lámina (referencia $n^{\circ}$ II en la imagen del plano de la sala) titulada «Los Parques Nacionales Argentinos» afirma que estos «... representan una de las formas más eficaces para conservar la diversidad cultural y natural del país, vinculandola con el desarrollo sustentable, generando así beneficios para todos». Además de la referencia a la diversidad cultural y natural del país, la lámina hace también mención a la importancia de los parques en funciones tales como: conservación de la biodiversidad; protección de yacimientos paleontológicos; resguardo de hábitats de especies amenazadas; preservación de los grandes escenarios del país; atesoramiento de variadas formas de relación entre las poblaciones y la naturaleza; posibilitar alternativas al desarrollo de comunidades locales; promoción de la educación y la recreación. En esta enumeración podemos encontrar un conjunto de misiones o

XIX y principios del XX en un contexto de expansión de la frontera productiva latifundista, el avance del Estado nación y la instalación de colonos. 
funciones de parques nacionales que remiten a distintos momentos del desarrollo histórico de las áreas protegidas. Así, por ejemplo, cuestiones de carácter estéticocontemplativo como preservar los grandes escenarios del país o, por otra parte, las referencias a las actividades recreativas, fueron - junto con funciones relacionadas a la soberanía territorial de un Estado en consolidación - misiones cuyo origen se remonta a la misma creación de las primeras áreas protegidas de nuestro país (REBORATTI 2OOO; SCARZANELLA 2OO2; FERRERO 2OI4, 2OI8; CARUSO 2OI5). Otros aspectos tales como la protección de especies amenazadas y sus ambientes son, en cambio, misiones que podemos relacionar con el surgimiento de las diferentes vertientes del ambientalismo a partir de la segunda mitad del siglo xx. Finalmente, las menciones al desarrollo sustentable, la educación y la conservación de la biodiversidad, reflejan objetivos planteados más recientemente, a finales del siglo pasado y que tomaron impulso luego de la reunión de Río de Janeiro de 1992 (REBORATTI 2000; SCARZANELLA 2002; CARUSO 20I5).

Otra diferencia entre el Museo de La Plata analizado por Descola y la sala de interpretación Maiá-Kú, se puede apreciar en la presencia de categorías híbridas que rompen con la separación tajante, aunque no jerárquica, entre la naturaleza y la cultura. La aparición de las especies introducidas por el hombre que ponen en peligro el hábitat es una muestra cabal de la tarea del parque: conservar la naturaleza. En este caso el riesgo no es la depredación de los bosques ni la contaminación, el riesgo son estos «simpáticos pero problemáticos» animales (referencia $n^{\circ} 8$ en la imagen del plano de la sala). La lámina que nos habla de estas «especies invasoras» ${ }^{13}$ se encuentra en la mitad cultural de la sala, espacialmente vinculados a los pueblos aborígenes. Estos animales invasores del hábitat son cuasi-naturaleza, ya que no son parte de la «naturaleza autóctona» y representan para el eje conservacionista

13] En dicho cartel se hace mención a las siguientes especies: salmón chinook (Oncorhynchus tshawytscha), el castor (Castor canadensis), la rata almizclera (Ondatra zibethicus), el visón (Mustela vison) y el conejo (Oryctolagus cuniculus). Es importante aclarar que el concepto de especie exótica invasora proviene de la biología y refiere a «plantas, animales o microorganismos que, habiendo sido trasladados más allá de sus límites naturales de distribución, consiguen establecerse y avanzar de manera espontánea en los nuevos ambientes donde son introducidos causando impactos severos sobre la diversidad biológica, la cultura, la economía y la salud pública». Disponible en: https://www.argentina.gob.ar/ambiente/biodiversidad/exoticas-invasoras (Ultimo ingreso: 10/08/2020). En este trabajo no negamos las consecuencias nocivas que dichas especies introducidas puedan tener. Entendiendo, además, que el concepto proviene del campo de la biología, nuestro objetivo es dar cuenta de procesos sociopolíticos de construcción de sentido que así como naturalizan grupos humanos también humanizan seres de la naturaleza. 
un riesgo para el hábitat. Así cómo usamos la noción de cuasi-cultura para dar cuenta de la interpretación que hacen en el parque nacional de humanos que están más cerca de la naturaleza que de la cultura, nos interesa traer la noción de cuasi-naturaleza para reflexionar sobre la representación de especies "naturales» que son interpretadas más cerca de la cultura que de la naturaleza. En el texto del folleto se refiere a estos animales de la siguiente manera:

«Existen también algunas especies de animales introducidas por el hombre hace varias décadas con fines económicos como el conejo europeo, el castor, la rata almizclera y el zorro gris. Estas especies se asilvestraron en un medio que no estaba preparado para soportarlas y por tal motivo algunas de ellas han causado algunos impactos muy serios en el paisaje natural. Un buen ejemplo de ello se observa en las áreas afectadas por las colonias de castores.»

Es necesario resaltar la representación de estas especies como «invasoras». La connotación negativa de esta representación, vinculado a cuestiones bélicas, al dominio de un territorio ajeno, no pasa desapercibida. Al ser especies «invasoras» son cuasi-naturaleza, dominan el territorio de las especies nativas y las ponen en «riesgo». Es importante aclarar que no estamos afirmando que nos encontramos frente a una cosmovisión que, en términos de DESCOLA (2005), podríamos definir como animismo, esto es, asignar a plantas y animales capacidades e instituciones derivadas de las de los seres humanos. Pero sí consideramos que relatos animistas son utilizados aquí como estrategias para justificar el control de especies introducidas en el marco de una cosmovisión predominantemente naturalista ${ }^{14}$ (DEsCOLA, 2005) que sin embargo, presenta coexistencia de fragmentos de mundos de sentido que el autor denomina hibridaciones.

Nos interesa asimismo destacar también la dimensión histórica y social que tienen estos relatos. Refiriéndose al uso de los recursos naturales en Argentina durante el modelo agroexportador de finales de siglo xix y principios del xx, Brailovsky y Foguelman afirman que «la conservación de la fauna autóctona no fue un objetivo prioritario durante la generación del 8O» (BRAILOVSKY Y FOGUELMAN, 2009: 190). Los autores encuentran la explicación en un modelo económico que insertándose

14] Según Descola, esta cosmología propia de la modernidad se define por una división fundamental entre lo humano y lo no humano. 
al capitalismo mundial llevaba adelante un proyecto de cambio total en el que todo lo autóctono es despreciado frente a lo extranjero, más precisamente lo europeo, que se erige como centro de la civilización y el progreso. En consonancia con este discurso, las elites gobernantes intentarán reemplazar «a la población autóctona por inmigrantes, a la vegetación natural por especies exóticas, a la arquitectura colonial por la francesa e italiana» (2009: 190). Como venimos observando, lo que muestra el caso del PNTDF es un giro de I80 grados respecto de estas representaciones, de acuerdo con los mismos autores este cambio se habría producido en nuestro país a partir de un aumento en la conciencia pública respecto de las cuestiones ambientalistas que se habría dado con en el fin de la última dictadura militar y la vuelta de la democracia en 1983.

Vimos que los animales introducidos aparecen como una de las justificaciones de la existencia del parque nacional. Por su parte, la folletería que se entrega a los visitantes señala que el parque protege 68.909 hectáreas, sin especificar ni de qué o quién, la noción de protección señala el riesgo potencial y la necesidad del Estado de conservar. Como ya anticipamos, entre aquello que debe ser conservado se encuentran las especies nativas. Los visitantes al parque reciben al abonar el ingreso un folleto sobre el huillín, una especie de nutria que habita el parque nacional y se encuentra en peligro de extinción. El PNTDF, según la folletería, protege el hábitat costero y asegura la conservación de esta especie. Sostiene que se dedican recursos para su estudio y conservación. Sin embargo, no es suficiente ya que señala la necesidad de preservar la franja costera para lograr la continuidad de esta especie en este «frágil» ecosistema. Nos interesa subrayar la noción de fragilidad del ecosistema asociado a esta justificación. Aquí, la fragilidad resulta coherente con los modelos dominantes de gestión de áreas protegidas, cuya «tendencia general (...) ha sido excluir a las poblaciones locales del acceso a los espacios protegidos, así como al uso de la flora, fauna, agua y tierra que allí se encuentren» (FERRERo, 2OI4:I2). Para el caso del PNTDF, las actividades de la población local general, como así también la de turistas y visitantes, son pensadas como productoras de un impacto negativo en dicho ecosistema; mientras que la preservación pasa a ser potestad de científicos y personal del parque o personal habilitado por la administración del mismo. El caso del huillín, sirve como paradigma de la configuración del sentido conservacionista que encontramos en la sala Maiá-Kú, ya que se busca evitar que un integrante «natural autóctono» sea «impactado» por las acciones de una «civilización» que no estaría integrada al medio natural. 


\section{CONCLUSIONES}

Propusimos reflexionar sobre las representaciones dicotómicas de cultura y naturaleza que aparecen en la sala Maiá-Kú del PNTDF. En directa relación con lo anterior, nos interesó también dar cuenta las formas de legitimación de la conservación de la naturaleza, «frágil» y «pasiva». Sobre esta última cuestión nos caben dos reflexiones finales a modo de cierre.

Primero. Sobre las cuasi-culturas y la cuasi-naturaleza. La dicotomía moderna cultura/naturaleza no clausura otros sentidos que podemos reconocer en, por ejemplo, la existencia de categorías híbridas. La definición de una categoría como cuasi o, por el contrario, como "pura» parece estar, en parte, determinada por el entrelazamiento con otro eje de interpretación: la dicotomía autóctono/ introducido. El esquema que sigue intenta presentar de manera sintética esta construcción discursiva:

ESQUEMA 1

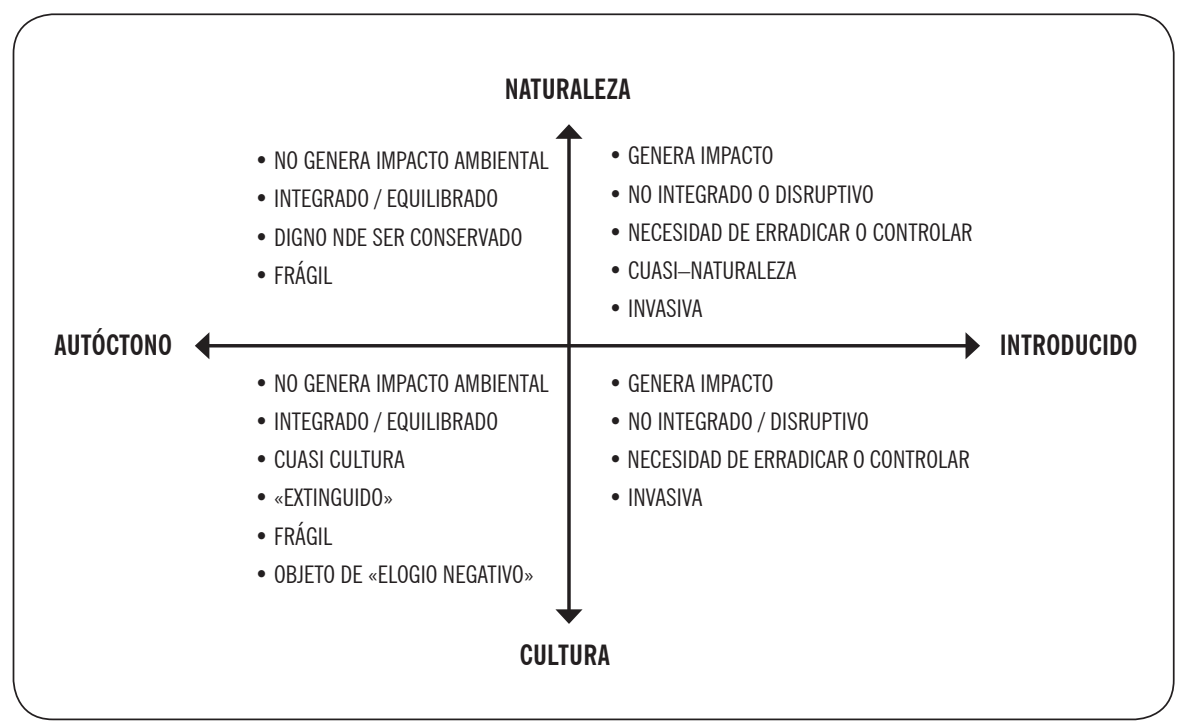


En esa unión los pueblos originarios autóctonos y «desaparecidos» no son un «riesgo", por ello son cuasi-culturas. Eran parte del paisaje ya que se integraban de «forma íntegra y efectiva a un ambiente inhóspito». Por el contrario, el riesgo es lo introducido, el riesgo es la cultura no autóctona. Por otra parte, las especies invasoras, introducidas por la cultura, son cuasi-naturaleza. Además, en la sala de interpretación se menciona a las culturas que sucedieron a los pueblos originarios y allí sí aparece la interpretación del impacto y lo disruptivo.

Es muy importante advertir al lector que dicho esquema no representa una estructura subyacente mental, ni psicológica ni de ningún tipo, no estamos afirmando ni consideramos tal cosa. Tampoco debe ser entendido como la reificación de una "cultura institucional», es simplemente un recurso que aquí utilizamos para mostrar de un pantallazo las configuraciones de sentido acerca del parque y sus integrantes. Este relato que la sala de interpretación ofrece al visitante es una construcción social resultado de disputas históricas que giran en torno a las formas particulares en que el Estado argentino se apropia de esos territorios que son las áreas protegidas.

En concordancia con nuestra afirmación acerca de que dicho relato no es la expresión de estructuras subyacentes, es importante mencionar algunas de las muchas excepciones a este esquema que existen en el parque y que, al menos en el material analizado, no parecen generar algún tipo de ruido. Así, es posible encontrar especies introducidas como la trucha sobre las que no pareciera haber acciones planificadas de erradicación ni control, existiendo incluso información sobre el dańo que han ocasionado a parte de la fauna ictícola nativa como el pez denominado puye (Galaxias maculatus). De la misma manera, encontramos actividades económicas, como el turismo, propias de la "cultura introducida», que a pesar de tener un impacto ampliamente visible e incluso advertido mediante cartelería en el parque, sigue siendo permitida ${ }^{15}$.

Segundo. Más allá de la reflexión interesante y necesaria sobre la conservación que se realiza en el PNTDF, entendemos que la idea dominante que aparece en la sala Maiá-Kú se sustenta en el modelo dicotómico cultura/naturaleza, donde las poblaciones locales solo pueden ser consideradas ajenas y por fuera de dichos

15] Como explicamos al inicio de este trabajo la creación del Parque Nacional Tierra del Fuego se dio en un contexto de búsqueda de soberanía en territorios limítrofes con Chile y donde el turismo funcionó como actividad promotora del desarrollo en la región. 
territorios y del manejo de sus recursos. Este modelo de conservación se acerca a la corriente del Ecologismo que, siguiendo a Martínez Allier, svampa (2008) denomina culto de la vida silvestre y caracteriza como una corriente con un registro biocéntrico, preocupada por conservar la naturaleza silvestre al tiempo que se opone al crecimiento de la población valorándose negativamente. Esta corriente encuentra respaldo científico en la biología de la conservación. Sus acciones buscan crear reservas en lugares con especies amenazadas o con mucha biodiversidad y que suelen ser poco respetuosas de las poblaciones nativas (svampa, 2008). Sin afirmar que esta sea la noción que domina el escenario en la Administración de Parques Nacionales, sí podemos plantear que es la idea de conservación que más se refleja en la sala Maiá-Kú. Tampoco aseveramos aquí que estos sentidos sobre la conservación sean únicos y monolíticos dentro de la institución, sino que entendemos que la norma es la convivencia de diferentes perspectivas y la disputa por los significados y las prácticas acerca de qué debe ser conservar y cómo debe hacerse.

IMAGEN 2:

PANEL REFERIDO A LOS «PUEBLOS CANOEROS».

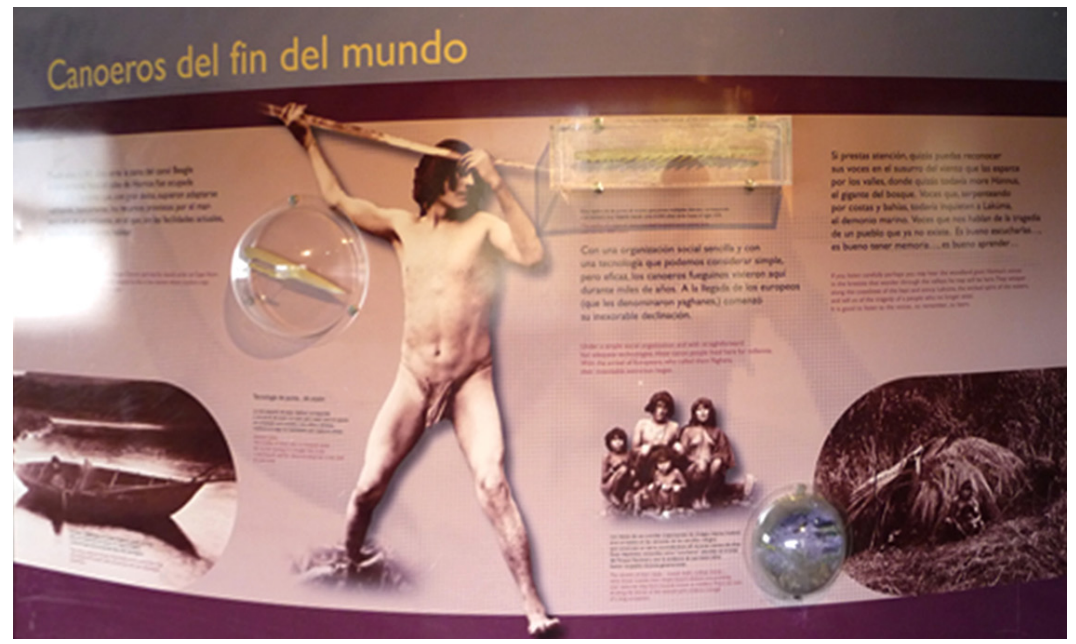

FUENTE: Foto de los autores. 
IMAGEN 3:

PANEL REFERIDO A LAS ESPECIES EXÓTICAS

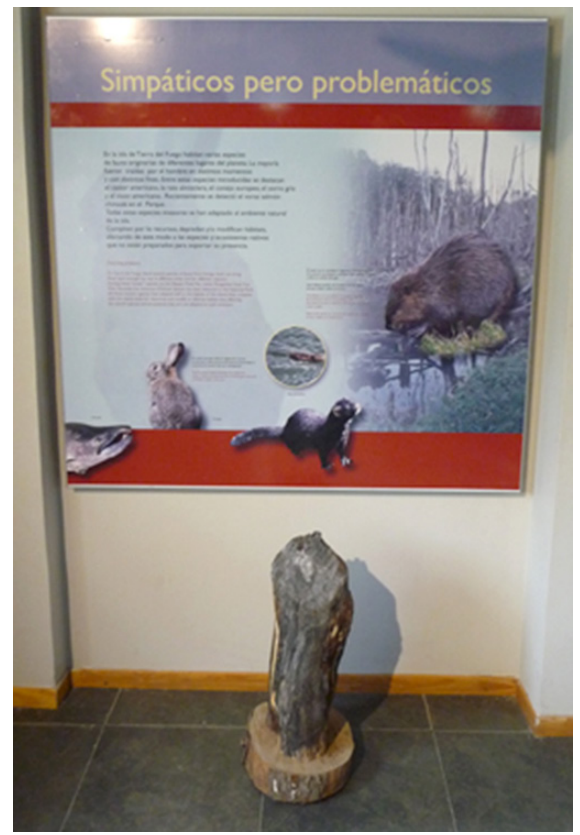

FUENTE: Foto de los autores.

\section{Referencias bibliográficas}

ADMINISTRACIÓN DE PARQUES NACIONALES (2007): formaciones provinciales de alteridad, Buenos Plan de manejo Parque Nacional Tierra del Aires, Antropofagia, pp. 11-43.

Fuego. Disponible en: https://sib.gob.ar/archivos/ PM_TIERRA_DEL_FUEGO.pdf

CARRERAS DOALLO, XIMENA (2012): «Parques nacionales y peronismo histórico. La patria mediante

APN (2013): Parque Nacional Tierra del Fuego Fauna Nativa: Huillín (Lontra provocax), Planta Orión YPF. BRAILOVSKY, ANTONIO Y FOGUELMAN, DINA (2009): Memoria Verde. Historia Ecológica de la Argentina, Buenos Aires, Editorial De Bolsillo.

BRIONES, CLAUDIA (2005): «Formaciones de alteridad: contextos globales, procesos nacionales y provinciales», en: BRIONES, CLAUDIA (comp.), Cartografías argentinas: Políticas indigenistas y la naturaleza», en: Estudios y Perspectivas del Turismo, № 5, volumen 21, pp. 1318-1335. CARUSO, SERGI0 (2015): "Análisis del Proceso de Creación de Áreas Naturales Protegidas por Parte de la Administración de Parques Nacionales en Argentina 1934-2015», en: Cardinalis, Año 3, №5, Departamento de Geografía, Facultad de Filosofía y Humanidades, Universidad de Córdoba, pp. 132-160 
DDIV-APN (2018): Parque Nacional Tierra del Fuego Información general, n/a.

DE CERTEAU, MICHEL (1999): La cultura en plural, Buenos Aires, Nueva Visión.

DESCOLA, PHILIPPE (2005): «Más allá de la naturaleza y la cultura», en: Etnografías Contemporáneas, número 1, pp. 93-111.

ERIZE, FRANCISCO; CANEVARI, MARCELO; CANEVARI, PABL0; COSTA, GUSTAVO Y RUMBOLL, MAURICIO ([1981] 1993): Los parques nacionales de la Argentina y otras de sus áreas naturales, Madrid, Editorial El Ateneo.

FERRERO, BRIAN (2014): «Conservación y Comunidades: Una Introducción», en: Avá, número 24, pp. 11-33.

FERRERO, BRIAN (2018): «Tras una definición de las áreas protegidas: Apuntes sobre la conservación de la naturaleza en Argentina», en: Revista Universitaria de Geografía, número 27, volumen 1 , pp. 99-117.

GERRARD, ANA CECILIA (2014): «El sigilo en las metáforas del viento: los Selknam y la retórica de la desaparición», en: XI Congreso Argentino de Antropología Social, Rosario.

GERRARD, ANA CECILIA (2015): Ya no saben cómo extinguirnos. Los Selk'nam de Tierra del Fuego: historia, territorio e identidad. Tesis de Licenciatura, Departamento de Antropología Social, Universidad Nacional de Misiones.

GERRARD, ANA CECILIA (2017): «Silcha, el agente de Policía: una aproximación a la conquista simbólica en el Territorio de Tierra del Fuego (19201940)», en: Conversaciones del Cono Sur 3 (1) Dossier Reemergencia indígena en los países del Plata: Los casos de Uruguay y de Argentina. Disponible en: https://conosurconversaciones. files.wordpress.com/2017/09/conversacionesdel-conosur-3-1-gerrard.pdf
LATOUR, BRUNO (2004): Nunca fuimos modernos, Buenos Aires, Editorial Siglo XXI.

MALLIMACI BARRAL, ANA (2008): "Y así me fui olvidando de irme. De Bolivianos/as en Ushuaia y sus modos de permanecer», en: 3as Jornadas de Historia de la Patagonia, San Carlos de Bariloche. MASOTTA, CARLOS (2018): «Represión, imágenes y silencios», en: Voces en el Fénix, la revista del plan Fénix, número 72, año 8, pp. 54-59. OYOLA-YEMAIEL, ARTHUR (2000): The Early Conservation Movement in Argentina and the National Park: A Brief History of Conservation, Development, Tourism and Sovereignty, Dissertation. com, USA.

PIGLIA, MELINA (2012): «En torno a los Parques Nacionales: primeras experiencias de una política turística nacional centralizada en la Argentina (1934-1950)», en: PASOS. Revista de Turismo y Patrimonio Cultural, $\mathrm{N}^{\circ} 1$, volumen 10, pp. 61-73.

REBORATTI, CARLOS (2000): Ambiente y sociedad. Conceptos y relaciones. Buenos Aires, Ariel. SCARZANELLA, EUGENIA (2002): "Las bellezas naturales y la nación: Los parques nacionales en Argentina en la primera mitad del siglo XX», en: Revista Europea de Estudios Latinoamericanos y del Caribe, 73, pp. 5-21.

SVAMPA, MARISTELLA (2008): "La disputa por el desarrollo: territorio, movimientos de carácter socioambiental y discursos dominantes», en: Cambio de época. Movimientos sociales y poder político. Buenos Aires: Siglo XXI.

VIDAL, HERNÁN J. (1993): «La calle dónde tú vives: paisaje urbano e identificación étnica en Ushuaia (Tierra del Fuego)», en: Publicar en Antropología y Ciencias Sociales, número 3, pp. 119-133. Disponible en: http://ppct.caicyt.gov.ar/index.php/ publicar/article/viewFile/1133/997. 